\title{
The Nature of the Relationship between Authors and Publishers
}

\section{A. Phillips, M.N.K. Saunders, S. Pandit, and D. D. Chetty}

Angus Phillips MA MBA is a Senior Lecturer and Field Chair at the Oxford International Centre for Publishing Studies, Richard Hamilton Building, Headington Campus, Oxford Brookes University, Oxford OX3 0BP United Kingdom

Mark N. K. Saunders BA MSc PGCE PhD is Head of Research and Reader in Research Methods at the Business School, Oxford Brookes University

Sue Pandit BA MBA is the Director of the Oxford International Centre for Publishing Studies

Deshini D. Chetty MSc MBA (Publishing) is the Commercial Manager, London Tests of English, Edexcel International

\begin{abstract}
Relationships within and outside organizations are changing, and the publishing sector is no exception. However, the roles of author and publisher remain distinct, each dependent on the other for the successful completion of a publishing project.
\end{abstract}

Drawing upon research conducted in the English Language Teaching Division of an international publishing company, this article examines the authorpublisher relationship within a service context. It considers the characteristics authors and publishers identify to be integral to the relationship, and explores the extent to which the expectations and perceptions of authors and publishers differ.

The research findings indicate that there is a mismatch between the characteristics that authors and publishers identify as integral to their relationship. Whilst publishers focus upon the role of the editor in the nurturing and maintenance of relationships with individual authors, authors consider their relationship to be with the whole publishing house, including the marketing and design functions. 


\section{Introduction}

Organizations are changing and the emergence of a flexible workforce is evident ${ }^{1}$. As a result, relationships within and outside organizations are changing and the publishing sector is no exception, relying heavily on freelance labour and outside agencies. Although the Internet has enabled a growth in self-publishing, in general the roles of author and publisher remain distinct, each dependent on the other to achieve their common aim, the successful completion of a publishing project.

The question that arises is: What is the key to successful author-publisher relationships? Research on the author-publisher relationship is limited, and the tendency in the industry has been to conduct the research from either the perspective of the author or the publisher. For example, the survey conducted in the UK by the Society of Authors in 2003 highlighted a range of grievances. These included poor publicity, lack of continuity in the editorial department, late payment of royalties and advances, and lack of communication by the publisher. "For authors, the lesson is simple: be prepared for disappointment with your publisher, and think yourself lucky if you have few complaints" 2 .

There is a need for research which examines the relationship from the point of view of both parties involved. Focusing upon the relationship as a service relationship poses the initial question - who is providing the service to whom? Authors are often identified as suppliers to publishing houses as the author supplies the raw material to the publisher ${ }^{3}$. However, the author's relationship with the publisher does not end with supplying the raw material. The publisher is offering services to the author to edit, design, print, promote and sell the work on the author's behalf. Asser argues that the publisher supplies a service to the author, since the publishing profession is inextricably linked to authorship and the market of readers and users ${ }^{4}$. He proposes that this link makes the publishing industry a "service industry", "serving both

1 N. Millward, A. Bryson, and J. Forth, All Change at Work? British employment relations 1980-1998 as portrayed by the Workplace Industrial Relations Survey series (London: Routledge, 2000).

2 The Author, CXIV, 1, Spring (2003), p.12.

3 G. Clark, Inside Book Publishing (London: Routledge, 2001).

4 P. J. Asser (1992), "Publishing, Copyright and the Public Good", Publishing Research Quarterly, Vol. 8, No. 2 (1992), pp. 5-11. 
authors and markets". 5 Balkwill says, in the context of their markets, "Publishers provide a service by assembling, organizing and disseminating knowledge" 6 .

Inevitably the role of service provider will vary according to the type of publishing, and whether the project is generated by the author or publisher. In educational publishing, for example, a project may be planned out in considerable detail before any author becomes involved. The publisher initiates the idea and then commissions an author to complete the task of supplying the material commissioned. The author then fulfils a contract through writing to a particular brief. This contrasts with trade publishers competing for a valuable author, who will have to prove that they can provide the very best service in terms of editorial, marketing effort, and sales. If their level of service fails to meet the expectations of the author, the writer may move on to another publishing house.

This article reports on research undertaken in the English Language Teaching (ELT) division of an educational publishing house. The company publishes a wide array of educational materials both for the UK and international markets, and like many publishers is committed to the maintenance of strong and effective author relationships. At the request of the company, the name of the company has not been used so as to maintain confidentiality. The name Edpub will be used to refer to the company.

Internal unpublished research undertaken within Edpub in the early 1990s had examined what the company was doing to enhance the creativity of its authors. The research found that authors expected publishers to provide enthusiasm, excitement, support, encouragement and a gate-keeping role. Professionalism and publishing expertise, including appropriate feedback skills, were expected from publishers. Authors assumed that publishers would respect their sense of ownership, and communicate clearly to them opinions about their work. In particular the research highlighted that authors perceived that the publishers were providing a service.

\footnotetext{
${ }^{5}$ Asser, p. 6.

${ }^{6}$ R. Balkwill, "Supporting Creativity in the Supply Chain: The role of creative teams in the authoring process", Publishing Research Quarterly, Vol. 15, No. 3 (1999), p. 34.
} 
The ELT market, which Edpub serves, remains attractive for publishers: "Overall, the ELT materials market has continued to show growth, because, globally, the demand for English learning persists, albeit on a lower growth track than in the 1980s" ${ }^{7}$. The latest published statistics (1999) indicate that there are 1,300 million ELT learners worldwide ${ }^{8}$. The need for good ELT authors is growing and Francis asserts that "the name of the author remains a critical success factor, and an important sub-brand in many cases" ${ }^{9}$. Most publishers would recognize the need to ensure that their relationship with the author, who is an integral part of the publishing value chain, is maintained successfully.

ELT publishing is set to continue to grow, as English is fast becoming the lingua franca of the world. At the same time there is growing competition in ELT publishing as local publishers penetrate domestic markets, reducing the market share of UK-based publishers. The local publishers' knowledge of the needs of the market and strong relationships with those who have the power to choose materials (government, educational authorities) gives them the leading edge over UK-based publishers. External customers are becoming more demanding and there is evidence of new entrants in the market ${ }^{10}$. However, Clark asserts that the major publishers expect their own growth to continue ${ }^{11}$.

The continuing success of publishers in the ELT market is dependent on many factors, one of them being the development and retention of creative authors. To investigate the dynamics of the author-publisher relationship, the following research question was posed:

To what extent do the expectations and perceptions of publishers and authors differ, in relation to the characteristics they identify to be integral to the author-publisher relationship?

\footnotetext{
${ }^{7}$ R. Francis, "Youngsters drive ELT Growth”, Bookseller, 23 May 2003, p. 26.

${ }^{8}$ R. Francis, “ELT Publishing”, in C. Gasson (ed.), Book Publishing in Britain (London:

Bookseller Publications, 1999).

9 Francis, 1999, p. 93.

${ }^{10}$ Francis, 1999.

${ }^{11}$ Clark, 2001.
} 


\section{Service}

Management literature offers various debates on the word "service". Services are usually described as "intangible" and their output as "an activity, rather than a tangible product" 12 . Thus, service is used to define non-manufacturing organizations and also organizations that meet the needs of society, such as public services. Gummesson however, recognizes a move towards the service paradigm in all sectors ${ }^{13}$. He argues that "customers do not buy goods or services in the traditional sense. They buy an offering and the value [may] consist of many components, some of them being activities (service) and some being things (goods). As a consequence, the traditional division between goods and services is long outdated" ${ }^{14}$. Thus the service user buys an "offering" from the service provider.

The literature proposes various suggestions and contradictory views on service quality. Definitions of service quality focus on the customers' expectations of the service deliverer and how well the service matches the customers' expectations ${ }^{15}$. The traditional approach is that service quality is a comparison of expectations and perceptions ${ }^{16}$. The expectations and perceptions of both service users and service providers can be analysed to highlight areas of the relationship that require improvement. This traditional approach focuses on the gap between the service users' expectations and perceptions across ten generic dimensions ${ }^{17}$.

\footnotetext{
${ }^{12}$ N. Johns, “What is this Thing called Service?", European Journal of Marketing, Vol. 33, No. 9/10 (1999), pp. 958-74.

${ }^{13}$ E. Gummesson, "Services Management: an evaluation and the future", International Journal of Service Industry Management, Vol. 5, No. 1 (1994), pp. 77-96.

${ }^{14}$ Gummesson, 1994, p. 2.

${ }^{15}$ G. Philip and S. A. Hazlett (1997), "The Measurement of Service Quality: A new P-C-P attributes method", International Journal of Quality and Reliability Management, Vol. 14, No. 3 (1997), pp. 260-86.

${ }^{16}$ A. Parasuraman, V. A. Zeithaml, and L. L. Berry, "A Conceptual Method of Service Quality and its Implications for Future Research", Journal of Marketing, Vol. 49, Fall (1985), pp. 4150; A. Parasuraman, V. A. Zeithaml, and L. L. Berry, "SERVQUAL: A multiple item scale for measuring consumers' perceptions and service quality", Journal of Retailing, Vol. 64, No. 1 (1988), pp. 12-40.

${ }^{17}$ A. Parasuraman, L. L. Berry, and V. A. Zeithaml, "Guidelines for conducting Market Research”, Marketing Research, Dec. (1990), pp. 34-44.
} 
1. Tangibles - physical evidence

2. Reliability - getting it right the first time, honouring promises

3. Responsiveness - willingness, readiness to provide service

4. Communication - keeping customers informed in a language they can understand

5. Credibility - honesty, trustworthiness

6. Security - physical, financial and confidentiality

7. Competence - possession of necessary skills and knowledge

8. Courtesy - politeness, respect, friendliness

9. Knowledge - understanding/knowing the customer

10. Access - ease of contact, e.g. opening hours, phones

The shortcomings of conceptualizing service quality in this manner have been debated widely in the service quality literature, with emphasis being placed upon the appropriateness of such generic measures as a basis for evaluating the quality of a specific service. Carmen argues that the dimensions that represent service quality are a function of a particular service and the industry within which it is located ${ }^{18}$. Philip and Hazlett confirm that different users of a service may assign different levels of importance to the same quality dimension ${ }^{19}$. Furthermore, the use of generic dimensions against which to measure a particular service's quality may not provide the detail necessary to assess the strengths and weaknesses of that service relationship ${ }^{20}$. As a result, such dimensions may fail to take account of the uniqueness and realities of specific services, and how they are interpreted and expressed by the parties involved. In addition, as such measures are used often from only the perspective of service user or deliverer, they may fail to reflect fully the dyadic nature of service encounters such as those between author and publisher.

\footnotetext{
${ }^{18}$ J. M. Carmen, "Consumer Perceptions of Service quality: An assessment of the SERVQUAL dimensions", Journal of Retailing, Vol. 66, No. 1 (1990), pp. 33-55.

${ }^{19}$ Philip and Hazlett, 1997.

${ }^{20}$ D. E. Rosen and C. Surprenant, "Evaluating Relationships: Are satisfaction and quality enough?”, International Journal of Service Industry Management, Vol. 9, No. 2 (1998), pp. 103-25.
} 
Problems of second order interpretation can also occur ${ }^{21}$ when data collected using traditional measures of service quality are subject to interpretation by a third party, such as a publisher. The person undertaking the inquiry may have filtered and added her or his own understanding to the language used and emphases placed by respondents, rather than it being understood and interpreted as intended ${ }^{22}$. Consequently, meanings in the data may be lost, or at best, misreported. Furthermore, traditional approaches do not normally require respondents to indicate the relative importance of quality constructs ${ }^{23}$. Such analyses usually involve the person undertaking the inquiry in making judgements about what is important, concentrating attention on those areas that they believe are of critical concern ${ }^{24}$. A publisher's judgement about which characteristics are key to the quality of service may therefore introduce bias to the analysis and future action.

An approach was therefore needed which reflects the dyadic nature of the author-publisher service relationship, allowing both sets of views to be captured and offering greater potential for understanding this relationship. In addition there was a need to accommodate the potentially different views and ensure that judgements made about the data collected reflected the views of both authors and publishers. To this end, a relatively new approach to measuring external and internal service relationships - the Template Process was adopted. Although this process has been applied to service relationships in various UK organizations, it has not yet been applied to the publishing industry.

\footnotetext{
${ }^{21}$ R. K., Yin, Case Study Research: Design and methods, 3rd edn (Thousand Oaks CA: Sage, 2003).

${ }^{22}$ W. Foddy, Constructing Questions for Interviews and Questionnaires: Theory and practice in social research (Cambridge University Press, 1994).

${ }^{23}$ F. F. Pitt, R. T. Watson, and C. B. Karan, "Service Quality: A measure of information systems effectiveness", MIS Quarterly, June (1995), pp. 173-87.

${ }^{24}$ Foddy, 1994; R. Krueger and M. Casey, Focus Groups: A practical guide for applied research, 3rd edn (Thousand Oaks, CA: Sage Publishing, 2000).
} 


\section{The Template Process}

Work by Saunders and Williams (2001) offers one approach to address such concerns ${ }^{25}$. Their Template Process was developed to illustrate the "fit" between the service provided and the needs of the users. The process acknowledges the uniqueness of each specific service, allowing those dimensions (characteristics) that users and providers believe are important to be defined separately and gaps between perceptions and expectations to be highlighted and recorded visually. Users and deliverers are selected using purposive samples based upon cases that were critical to the service, with the quality perceptions and expectations being captured separately. As part of the process, service users and providers independently defined those characteristics that were important to them in terminology specific to the service. For example, the characteristic "Staff appearance" has been defined through the extremes of "smart" and "scruffy." Subsequently, service users' and providers' perceptions and expectations for each of their own characteristics are located upon its continuum. Each resulting Service Template therefore reflected the language, terminology and priorities specific the service users or providers who produced it, with gaps between perceptions and expectations highlighting where action might be needed. Subsequently users and providers can work together with a facilitator to develop an agenda for action to improve the service relationship. In this research the Template Process was structured around three phases:

\section{Phase I: Sample selection}

Purposive samples were drawn from both authors and publishers focusing upon obtaining critical cases from which logical generalizations may be made, regarding the key themes. Two publishing projects were identified for the research and participants were chosen from these projects. These projects were decided upon by examining current projects at Edpub and identifying authors and publishers who as well as working on current projects had also worked

\footnotetext{
${ }^{25}$ M. N. K. Saunders and S. W. Williams, "Double-Loop Learning and improving Organizational Relationships: The application of the template process", Current Topics in Management, Vol. 6 (2001), pp. 127-48. See also M. N. K. Saunders and C. S. Williams, "Towards a New Approach to understanding Service Encounters: Establishing, learning from and reconciling different views", Journal of European Industrial Training, Vol. 24, No. 2/3/4 (2000), pp. 220-7.
} 
together previously. This ensured that the participants were experienced in their roles and had a long-term relationship with the company. This, it was argued, would provide them with a clear insight into the characteristics that made up the author-publisher relationship and the nature of that relationship within the company. Eight authors and publishers/editors contacted agreed to partake in the research. This resulted in two groups of authors and two groups of publishers.

\section{Phase II: Template generation and validation}

Separate meetings, approximately two hours long, were held by a facilitator with each of the author or publisher groups. Each meeting followed a fourstage process during which a separate Template was generated ${ }^{26}$ :

Stage 1: Preparation. The purpose and nature of the process was explained and meanings of terms clarified. The situation to be considered, the authorpublisher relationship, was displayed prominently and referred to regularly to help maintain focus.

Stage 2: Explore service characteristics. The characteristics of the authorpublisher relationship were elicited and recorded in the order they emerged using the participants' words through a brainstorming type process.

Clarification of meanings was sought; thereby helping ensure everyone in the meeting was using a similar frame of reference and had the same understanding. Subsequently, the list of characteristics was refined and descriptors generated for the extremes of each. For these, participants were asked to suggest the "ideal" situation and the "worst" case, the resulting bipolar rating scales defining these extremes. For example, for one group of authors the characteristic "Feedback - quality" was defined by extremes of "painstaking, perceptive" and "antagonistic" (figure 1).

Stage 3: Plot perceptions and expectations against identified characteristics. A visual representation (template) was then built by recording first the expectations and then the perceptions for each characteristic relative to the extremes on a ten-point scale (figures 1 and 2). For each characteristic, perceptions were defined through answers to the question "What do you perceive to be the position today?" and expectations through "What could reasonably be expected?" These questions were repeated for each of the

\footnotetext{
${ }^{26}$ Saunders and Williams, 2001.
} 
characteristics. The responses for both perceptions and expectations were recorded against the ten-point bi-polar scale, with one representing the negative extreme and ten representing the positive extreme. Participants discussed with each other how these should be recorded. Where participants had a range of views this was represented by the length of the bar (figures 1 and 2).

Stage 4: Interpret and validate issues. Each completed template was then discussed with those generating it. This helped confirm the internal validity of the template and those characteristics important in author-publisher relationship have been captured. Finally, participants were asked to score those characteristics they consider most important by allocating 100 points between them and giving no characteristic less than ten points. This forced participants to identify those characteristics in the author-publisher relationship that they considered "most important" rather than dividing points amongst all characteristics. It is these weighted characteristics that are shown in figures 1 and 2.

\section{Phase III: Exploration, learning and possible action}

In Phase III of the Saunders and Williams process ${ }^{27}$ the templates are used as catalysts for those involved to explore and gain insights into each other's perceptions and expectations of the service relationship, prior to developing a joint agenda for possible action. However, due to time and resource constraints this stage of the process was not conducted in the manner proposed by Saunders and Williams ${ }^{28}$. Instead the researchers interpreted the templates by comparing and contrasting them.

\section{Template Results}

Author group 1 chose to prioritize seven groups of characteristics as important allocating 100 points amongst them. Groups of characteristics associated with "Feedback", "Design material" and "Royalties" were considered the most

\footnotetext{
${ }^{27}$ Saunders and Williams, 2001.

${ }^{28}$ Saunders and Williams, 2001.
} 
Fig. 1 Extract from Templates generated by the two author groups (weighted characteristics)

Author group 1

\begin{tabular}{|c|c|c|c|c|c|c|c|c|c|c|c|c|c|}
\hline CHARACTERISTIC & $W T$ & IDEAL & 10 & 9 & 8 & 7 & 6 & 5 & 4 & 3 & 2 & 1 & WORST \\
\hline Feedback -quality & ) & painstaking, perceptive & & e & ep & $\mathbf{p}$ & p & $\mathbf{p}$ & p & $\mathbf{p}$ & & & antagonistic \\
\hline Feedback -time & $\mid 20$ & constructive, punctual & & & $\mathbf{e}$ & & $\mathbf{p}$ & & & & & & missing deadlines \\
\hline Feedback -reviews & ) & good samples & & & & & $\mathbf{e}$ & p & & & & & no classroom connection \\
\hline Design material -material works & 20 & clear signposting & & ep & p & p & $\mathbf{p}$ & $\mathbf{p}$ & p & $\mathbf{p}$ & p & & lack of cohesion \\
\hline Design material -feel of material & ) & distinctive, original & & ep & p & $\mathbf{p}$ & p & p & p & $\mathbf{p}$ & $\mathbf{p}$ & & too 'TEFLy' \\
\hline Royalties -negotiation & 20 & good royalty share & & & e & & & p & & & & & basic percentage \\
\hline Royalties-feedback & ) & knowledge-sale, markets & & & & & e & & p & & & & author lacks knowledge \\
\hline Author treatment & 10 & fair share of resources & & & & & $\mathbf{e}$ & & & p & & & few receive - more resources \\
\hline Versions -creation & 10 & in major markets & & & $\mathbf{e}$ & & & & & p & & & lack of any \\
\hline Versions -consultation & ) & co-ordination -early stage & & & e & & & & p & & & & publisher dictates \\
\hline Add-ons & 10 & soon after publication & & & & $\mathbf{e}$ & & & p & p & $\mathbf{p}$ & & bad quality \\
\hline Marketing -quality & ) & varied & & & $\mathbf{e}$ & & p & $\mathbf{p}$ & p & p & & & no advertising \\
\hline Marketing -campaigns & $\mid 10$ & reaches teacher & & & & ep & $\mathbf{p}$ & $\mathbf{p}$ & $\mathbf{p}$ & $\mathbf{p}$ & & & misses target \\
\hline Marketing -author travel & ) & reaches target & & & & ep & p & $\mathbf{p}$ & p & p & & & unplanned \\
\hline & & expectations & $\mathbf{e}$ & & & & & & \multicolumn{5}{|c|}{ perceptions } \\
\hline
\end{tabular}


Author group 2

\begin{tabular}{|c|c|c|c|c|c|c|c|c|c|c|c|c|c|}
\hline CHARACTERISTIC & $W T$ & IDEAL & 10 & 9 & 8 & 7 & 6 & 5 & 4 & 3 & 2 & 1 & WORST \\
\hline Publisher supportive & 20 & all stages of the process & & & ep & & & & & & & & no involvement \\
\hline Editorial team & 20 & creative, thorough & p & & e & & & & & & & & no team consistency \\
\hline Marketing quality & 10 & creative, dynamic & & & e & p & & & & & & & no evidence \\
\hline Efficient use of time & 10 & not time-wasting meetings & & & e & p & & & & & & & reluctance to meet \\
\hline Promotional trips & 10 & complete support & e & & $\mathbf{p}$ & & & & & & & & inefficient service to author \\
\hline Feedback -piloting & ) & constructive reports & & & ep & & & & & & & & unanalytical (sic) reports \\
\hline Feedback -book published & $\mid 10$ & feedback on market sales & & & e & & & $\mathbf{p}$ & & & & & no communication (author) \\
\hline Feedback -preparation level & $\mid$ & good research & & & e & & $\mathbf{p}$ & & & & & & misidentify level \\
\hline Feedback -focus groups & ) & analytical report -summary & & & e & & $\mathbf{p}$ & & & & & & small numbers \\
\hline Deadlines -publisher & 10 & meet all deadlines & e & & & p & & & & & & & missing deadlines \\
\hline Deadlines -author & ) & meet all deadlines & ep & & & & & & & & & & missing deadlines \\
\hline New projects -receptivity to & ) & trust established authors & & & e & & p & & & & & & no interest in authors' ideas \\
\hline author & $\mid 10$ & & & & & & & & & & & & \\
\hline New projects - planning ahead & ) & plan ahead for authors & & & $\mathbf{e}$ & & & & & & p & & not an issue for publisher \\
\hline & & expectations & e & & & ap & & p & \multicolumn{3}{|c|}{ perceptions } & & \\
\hline
\end{tabular}


Fig. 2 Extract from Templates generated by the two publisher groups (weighted characteristics)

Publisher group 1

\begin{tabular}{|c|c|c|c|c|c|c|c|c|c|c|c|c|c|}
\hline CHARACTERISTIC & $W T$ & IDEAL & 10 & 9 & 8 & 7 & 6 & 5 & 4 & 3 & 2 & 1 & WORST \\
\hline Attitude -understanding & $\longdiv { 2 6 }$ & mutual & & & ep & e & & & & & & & defensive \\
\hline Attitude -work and ability & ) & confidence & & & ep & $\mathbf{p}$ & & & & & & & lack of respect \\
\hline Common aim -quality product & $\longdiv { 2 0 }$ & compromise to achieve aim & & p & ep & & & & & & & & author misunderstands aim \\
\hline Common aim -working together & ) & appreciate benefits of team & & & ep & $\mathbf{p}$ & & & & & & & 'them and us' attitude \\
\hline Feedback -process & 12 & put process into practice & & & & $\mathbf{e}$ & & & & p & p & & minimal-lack of time \\
\hline Feedback -people & ) & all within project involved & & & e & & & & & p & & & minimum involvement \\
\hline Team dynamics -define roles & ) & educate author & & p & $\mathbf{e}$ & $\mathbf{e}$ & & & & & & & author -no appreciation \\
\hline Team dynamics -working & $\mid 12$ & harmony & & & ep & & & & & & & & breakdown \\
\hline relationship[ & | & & & & & & & & & & & & \\
\hline Team dynamics -team building & ) & appreciate creative juices & & & ep & & & & & & & & lose sight of team \\
\hline Manage relationships & 10 & strong personality managed & & & $\mathbf{p}$ & ep & e & & & & & & dominance of one author \\
\hline Responsiveness & 10 & immediate action & & ep & & & & & & & & & author feels ignored \\
\hline Reliability (author) & 10 & prompt/effective work & & & $C_{1}$ & & & & & & & & task not completed on time \\
\hline & & expectations & e & & & & & p & \multicolumn{3}{|c|}{ perceptions } & & \\
\hline
\end{tabular}




\section{Publisher group 2}

\begin{tabular}{|c|c|c|c|c|c|c|c|c|c|c|c|c|c|}
\hline CHARACTERISTIC & $W T$ & IDEAL & 10 & 9 & 8 & 7 & 6 & 5 & 4 & 3 & 2 & 1 & WORST \\
\hline Trust & 30 & author trusts input -publisher & & & ep & & & & & & & & $\begin{array}{l}\text { author's work changed into } \\
\text { something s/he doesn't want }\end{array}$ \\
\hline Communication -quality & 20 & clear, comprehensive & & & $\mathbf{e}$ & p & p & & & & & & misunderstanding, breakdown \\
\hline Communication -channels & 10 & parties speak when want to & & & ep & & & & & & & & no contact -critical moments \\
\hline & & expectations & e & & & & & p & \multicolumn{4}{|c|}{ perceptions } & \\
\hline
\end{tabular}


important and allocated 20 points each. Groups of characteristics associated with "Versions" (creation and consultation) and "Marketing" were each allocated 10 points as were "Author treatment" and "Add-ons" (supplementary materials such as CD-ROMs and web pages). In contrast, author group 2 highlighted eight characteristics of the relationship. "Publisher - supportive" and the "Editorial team" were viewed as the most important characteristics, each being allocated 20 points. The characteristics "Marketing - quality", "Efficient use of time", "Promotional trips", and the groups of characteristics associated with "Feedback", "Deadlines" and "New projects" were all allocated 10 points.

The two author templates revealed shared characteristics in relation to feedback, deadlines, author treatment, marketing and author trips. Author group 2 highlighted the characteristic of support to the author, with the positive extreme being "in all stages of the process". Other issues raised were in the areas of design and royalties (group 1) and new projects and the nature of the editorial team (group 2).

The template for author group 1 displays a range of opinions as to perceived performance. This is especially apparent in the areas of design and marketing. There were clear gaps between expectations and perceptions in four areas. The first gap concerned royalties, where the authors had recorded expectations close to the ideal of a "good royalty share" whilst perceiving that the actual position was closer to a "basic percentage". The next gap concerned the treatment of authors. Here authors perceived that the position was close to their worst case of "few receive - more resources" whilst feeling that it would be reasonable to expect treatment which was slightly close to a "fair share of the resources". The creation of different "Versions" of the product was another area where these authors' expectations did not match their perceptions of reality. Authors perceived either that none were being created, or that the "publisher dictate[ed]", there being little consultation. For the characteristics of "Feedback", "Design material", and "Marketing", the wide variations in perceptions provided clear indications of some unhappiness with the perceived publisher performance from some of the authors.

In contrast, the Template for author group 2 shows a clear uniform view of the perceived publisher performance with no spread of either perceptions or expectations. Unhappiness with perceived performance is evident for all but one of the group of characteristics related to "Feedback". In particular these 
authors felt there was a gap between their expectations and performance for feedback on sales and aspects of market research. With regard to deadlines, these authors perceived that whilst they met publishers' expectations of "meet[ing] all deadlines", the publishers did not meet their expectations. For "New projects", these authors also saw a big gap between expectations and perceived performance. In particular they expect publishers to plan ahead for their authors, but perceived that the publishers did not consider that this was an issue.

Publisher group 1 weighted seven of the characteristics they identified, the most important being those related to "Attitude". These covered "understanding" of each other and "work and ability". Characteristics related to the realisation of a "Common aim" were rated as the second most important being allocated 20 points. Characteristics associated with "Feedback" and "Team dynamics" were allocated 12 points each. The ability of the publisher to "Manage relationships", their "Responsiveness ", and the "Reliability" of the author were each allocated 10 points. Publisher group 2 weighted a smaller number of characteristics. Within these "Trust" was considered most important being allocated 30 points whilst two characteristics associated with "Communication" - "quality" and "channels" - were allocated a further 30 points between them. The characteristics "Guidance" and "Stability" were allocated 20 points each.

In contrast to the authors' Templates, those created by the publishers suggest that they could see few gaps between expectations and performance. One gap, highlighted by Publisher group 1, related to their perceptions of the feedback process, which were closer to their worst case of "minimal - lack of time" than they felt could be reasonably expected. This was reflected in publisher group 2's characteristic of "communication - quality" which they perceived did not meet expectations of being "clear [and] comprehensive." Elsewhere there appeared to be considerable similarity in the characteristics identified by the two groups of publishers, and a close match between perceptions and expectations.

\section{The Author-Publisher Relationship}

The publishers and authors recognized the need for the publisher to provide guidance and support. There was a recognition by both publishers and authors 
of a gap between expectations and perceptions with regard to the feedback process. In their discussions when creating their Templates, authors and publishers highlighted the importance of a consistent editorial team, this being the authors' point of contact with the publishing house. Both publishers and authors indicated that perceptions exceeded reasonable expectations, suggesting satisfaction with the basic working relationship.

Both groups of authors indicated that they wanted feedback on "sales in each market" and that there was a gap between what they considered to be reasonable expectations and their perceptions. The authors indicated that this knowledge would help them in their preparation for new projects. They highlighted a gap between expectations and perceptions with regards to promotional trips. Moreover, the largest gap between perceptions and expectations related to planning ahead for the author team - they felt that the publisher should be looking after their future career.

The two groups of publishers shared a similar view with regards to the characteristics of the relationship. Attitude, feedback and responsiveness, communication, and team dynamics, identified by the first group of publishers, are similar to trust, guidance, communication and a consistent editorial team, identified by the second group. All the characteristics prioritized by the second group of publishers were prioritised by the first focus group. This suggests the existence of a common view within the company.

The publishers identified characteristics that focused on building and maintaining relationships. Their perceptions of the relationship were based on what they, as individuals, could do for the author. In particular they identified characteristics that related to nurturing and building relationships. Their focus was on developing an effective working relationship with the author.

By contrast authors identified a wider variety of characteristics relating to sales of the product or the development of future projects (marketing, add-ons, author travel, the commissioning of new projects). Discussion during the creation of their templates showed that the authors perceived the authorpublisher relationship to be one with the publishing house and not a specific editor or editorial team. Although the templates for the two groups of authors were different, they reflected characteristics concerned with the whole publishing process, not just their relationship with the individual publisher. The first group identified marketing and design characteristics, the second 
marketing quality and promotional trips. Overall the characteristics depicted what the service provider (publisher) could do for the service user (author). Author group 2 explicitly used the phrase "inefficient service to author".

It is interesting to note that there is a similarity between the characteristics and the findings of the previous research conducted at Edpub. Mutual respect and negotiation are common factors in both sets of research. The need for the publisher to support the author was recognised in the templates of both authors and publishers in Group 2 and was one of the key findings in the earlier research.

\section{The Idea of Service}

In answer to those suspicious of the idea that the relationship between author and publisher can be viewed in the context of a service, it is interesting to return to the generic set of service quality dimensions outlined earlier ${ }^{29}$. These are: tangibles, reliability, responsiveness, communication, credibility, security, competence, courtesy, knowledge and access.

Looking at the set of characteristics identified by the author groups, there are similarities to the generic list in the areas of reliability (e.g. publisher being supportive, meeting deadlines), responsiveness (feedback), communication (feedback), and knowledge (receptive to author). Security could cover the issue of a fair royalty, and tangibles could cover design and marketing quality. The publishers identified explicitly the characteristics of responsiveness and credibility (by the publisher), reliability (but on the author's part), and communication (in both directions). Other dimensions such as courtesy and access would normally be taken for granted as part of an author/publisher relationship.

\section{Conclusion}

The key findings of the research are:

\footnotetext{
${ }^{29}$ Parasuraman et al., 1988.
} 
- There is a mismatch between the characteristics identified by authors and publishers.

- Both authors and publishers indicate the importance of a consistent editorial team.

- Both authors and publishers indicate gaps between expectations and perceptions with regards to the feedback process.

- Authors indicate a gap between expectations and perceptions with regards to feedback on sales and promotional trips.

- Authors attribute importance to having their author career managed by publishers.

Overall the publishers did not perceive many gaps between their expectations and perceptions. The authors, however, considered that there were gaps between expectations and perceptions, suggesting that the authors believe that the relationship could be improved. It could also be argued that the publishers' perception that the relationship is working successfully is a misconception.

The range of characteristics selected by the authors revealed that they perceived the author-publisher relationship to be one with the publishing house and not a specific editor or editorial team. Characteristics included issues from the marketing and design functions. This is a change from the established view:

The tradition of publishing houses was that the author/editor relation was what bound a successful author to the house: the editor was a necessary midwife to the author's prose. It was the author/editor bond that acted as a book's collateral when contracts were negotiated ${ }^{30}$.

The author's increasing desire for contact with other parts of the publishing company needs to be fully recognized by publishing houses.

The author ... may come into contact with more parts of the company than just the commissioning editor, and play a part in both the design and appearance of the title, as well as contributing to its initial sales and marketing impact ${ }^{31}$.

\footnotetext{
${ }^{30}$ Gardiner, J., "What is an Author? Contemporary publishing discourse and the author figure”, Publishing Research Quarterly, 2000, Vol. 16, No. 1 (2000), p. 67.

${ }^{31}$ Balkwill, 1999, p. 32.
} 
A limitation of the research was that the Template Process was not used in its entirety and therefore the issues could not be fully explored with authors and publishers together. Although critical cases were identified as samples, the projects being worked on varied in their success. This will have impacted on the results, which were found to vary between the two sets of participants. Furthermore, although all parties were involved in current projects, their projects were at different stages.

The research suggests that further author awareness training is needed in the publishing house. Publishers/editors need to be aware of the authors' perception of the characteristics of the relationship, whilst in turn authors need to be made aware of how publishers view the relationship.

It was evident from the research that the Template Process could be used to provide an insight into the characteristics of the author-publisher relationship and the gaps between expectations and perceptions of both parties in the relationship. Identifying the gaps provides areas in which both parties can work to improve the relationship. Used in its entirety the Template Process provides a framework that can enable organizational learning. This is achieved by letting the participants take ownership for an action plan, having shared in the analysis of the issues.

It is proposed that further research examine author-publisher relationships in other sectors of the publishing industry including academic, trade and journal publishing. It would be interesting to explore how the nature of the relationship differs between sectors, as according to the kind of publishing the service relationship may be more or less explicit. With the present debates surrounding open access publishing, journals publishing would be a particularly fruitful area. Further research should use the Template Process in its entirety, allowing the participants to engage more fully in the process. The method used in this research can also be applied at other points in the publishing value chain to examine a variety of relationships, whether between different parts of an organization or between organizations. 